\title{
Yonca Kuru Otu ve Süt Sığırı Rasyonuna Zeolit ve Meşe Palamudu İlavesinin in Vitro Organik Madde Sindirimi ve Metan Oluşumu Üzerine Etkisi ${ }^{* *}$
}

\author{
Zeynettin ECE ${ }^{1}$, Mehmet AVCl ${ }^{2 *}$ \\ ${ }^{1}$ Harran Üniversitesi, Sağlık Bilimleri Enstitüsü, Şanlıurfa, Türkiye. \\ ${ }^{2}$ Harran Üniversitesi, Veteriner Fakültesi, Hayvan Besleme ve Beslenme Hastalıkları Anabilim Dalı, Şanlıurfa, Türkiye.
}

Özet: Bu çalışma, süt sığııı rasyonu (SSR) ve yonca kuru otuna (YKO) farklı seviyelerde ilave edilen meşe palamudu, meşe palamudu + zeolit'in metan $\left(\mathrm{CH}_{4}\right)$ gazı oluşumu, in vitro organik madde sindirimi (iVOMS), metabolik enerji (ME) değeri ve rumen amonyak azotu ( $\left.\mathrm{NH}_{3}-\mathrm{N}\right)$ üzerine etkisini belirlemek amacıyla yapılmıştır. YKO ve SSR 'na \%0 (kontrol), \%2.5, \%5, \%10 meşe palamudu ve aynı seviyelere $\% 2.5$ zeolit ilave edilerek toplam 16 grup oluşturulmuştur. Farklı seviyelerde meşe palamudu ve meşe palamudu + zeolit ilave edilmiş SSR ve YKO in vitro gaz üretim tekniği ile 24 saatlik inkubasyona bırakılmıştır. İnkubasyon sonunda oluşan toplam gaz içerisindeki $\mathrm{CH}_{4}$ ve karbondioksit $\left(\mathrm{CO}_{2}\right)$ gazı oranları özel bir cihaz ile ölçülmüştür. SSR ve YKO için en düşük $\mathrm{CH}_{4} \% 10$ meşe palamudu grubundan elde edilmiştir $(\mathrm{P}<0.001)$. SSR'u ve YKO'na ilave edilen palamut seviyesiyle orantılı olarak 24. saat rumen sıvısı $\mathrm{NH}_{3}-\mathrm{N}$ değeri azalırken iVOMS ve ME değerleri artmıştır $(\mathrm{P}<0.001)$. Sonuç olarak meşe palamudu ilavesinin, rumende yıkılan protein miktarını azaltarak, by pass proteinleri, iVOMS ve $\mathrm{ME}$ değerini artırabileceği ve yüksek düzeyde kullanıldığında $\mathrm{CH}_{4}$ gazı üretimini azaltabileceği kanısına varılmıştır. Çalışma sonuçları dikkate alındığında meşe palamudu ve zeolitin hayvan performansı üzerine etkilerinin anlaşılmasında in vivo çalışmalara ihtiyaç olduğu söylenebilir.

Anahtar Kelimeler: Meşe palamudu, Metan, Zeolit, in vitro sindirilebilirlik.

\section{Effect of Zeolite and Acorn Added to Alfalfa Hay and Dairy Cattle Ration on In Vitro Organic Matter \\ Digestibility and Methane Production}

\begin{abstract}
This study was conducted to determine the effects of acorn and acorn+zeolite mixture added to dairy cattle ration and alfalfa hay on in-vitro methane production, in-vitro organic matter digestion, metabolic energy value, rumen ammonia nitrogen and nutrient composition. Sixteen groups were formed by adding $0 \%$ (control), $2.5 \%, 5 \%, 10 \%$ acorn in combination with $2.5 \%$ zeolite to alfalfa hay and dairy cattle ration. Feed samples added with different levels of acorn and acorn-zeolite mixture were a incubated in glass tubes for 24 hours using in-vitro gas production technique. After 24 hours, methane and carbon dioxide gas levels were determined by a methane measuring device. The lowest methane production for dairy cattle ration and alfalfa hay were observed in the group added with $10 \%$ acorn $(P<0.05)$. Along with the levels of acorn, ammonia nitrogen values were decreased, while in-vitro organic matter digestion and metabolic energy values increased $(P<0.001)$ fordairy cattle ration and alfalfa hay. Consequently, it was concluded that, acorn might increase the bypass proteins, in-vitro organic matter digestion and metabolic energy value by decreasing the degradation of feed protein in rumen, and decrease methane production if it is added in a high level. Besides, effects of acorn and zeolite on animal performance should be investigated by in-vivostudies.
\end{abstract}

Keywords: Acorn, Zeolite, Methane, In vitro digestibility.

\section{Giriş}

îklim değişikliği ve küresel ısınma, dünyadaki canlıların yaşamını tehlikeye düşürebilecek çok büyük bir problem olarak bilinmektedir (Sağlam ve ark., 2008). Sanayi ve hayvancılı̆̆ın gelişmesine bağı olarak açığa çıkan sera gazları $\left(\mathrm{CO}_{2}, \mathrm{CH}_{4}, \mathrm{~N}_{2} \mathrm{O}, \mathrm{O}_{3}\right.$, CFCs) küresel ısınmaya sebep olmaktadır (Çepel, 2003). Ruminatlar tarafından yemle alınan toplam enerjinin \%2-12'si metan üretimi nedeniyle kaybedilmektedir (Canbolat ve ark., 2011). Yetişkin sığırların rumenlerinde bir günde meydana gelen metan gazı yaklaşık 300 litre olarak kabul edilmektedir (Breves ve Leonhard, 2000). Metan gazında bulunan enerjiden ruminant hayvanlar faydalanamaz ve geğirmeyle (ruktus) dışarıya atılır. Bundan dolayı, metan gazı hem ekonomik hem de ekolojik sorunlara sebep olmaktadır. (Öztürk, 2008). Tanenler yapı olarak kondanse ve hidrolize olmak üzere iki grupta incelenir. Hidrolize olan tanenlerin temel yapısı ise gallik asitdir. Yapısında kondanse tanen bulunan bitkilerin metan oluşumunu düşürdüğüne dair araştırmalar yapılmıştır (Animut ve ark., 2008; Woodward ve ark., 2002). Hidrolize 
yapılı tanenler direkt metan gazı oluşturan mikroorganizma ile hidrojen molekülünü üreten bakterilere etki etmektedirler. Kondanse tanenler selüloz sindirimini düşürerek metan gazını azaltır (Goel ve Makkar, 2012). Yeme, kuru maddenin \%0.025 seviyesinde ilave edilen akasya bitkisi kaynaklı tanenin metan gazı oluşumunu \%13 oranında düşürdüğü tespit edilmiştir (Carulla ve ark., 2005). Başka bir çalışmada ise kaba yeme \%20 seviyede akasya bitkisi eklenmesinin metan gazı oluşumunu önemli ölçüde düşürdüğü bildirilmiştir (Hariadi ve Santoso, 2010). Saponinler yem maddesi olarak kullanılan birçok bitkide bulunan glikozit yapıdaki bileşikler olup özellikle protozoaların üremesine olumsuz etkileri nedeniyle metan gazı oluşumunu baskı altına almaktadır (Patra, 2010). Bu maddeler, metanın oluşması için gerekli olan hidrojen iyonunun meydana gelmesini sınırlandırarak metan oluşumunu düşürmektedir (Guo ve ark., 2008). Koyunlarda yapılan çalışma sonucuna göre, saponin kapsayan bitkilerin (Yucca schidigera, Sapindus saponaria, tannik asit) rasyolarına ilave edilmesi metan gazı oluşmasını \%10-27 düzeyinde azaltmıştır (Doreau ve ark., 2011).

Türkiye'deki ormanlarda önemli bir yer tutan meşe ağaçları her yıl önemli miktarda palamut üretmesine rağmen yetişen palamutlar değerlendirilmemektedir. Ülkemizde 18 farklı meşe türü mevcuttur. Meşe türlerinin meyvesi olarak bilenen palamut, geçmişten beri yem maddesi olarak hayvanlara verilmektedir. Kabuğu soyulmuş olan palamud'un azotsuz öz madde bakımından zengin olduğu bilinmektedir. Meşe palamudu \%5 ila \%8 civarında tanen içerir. Tanenlerin neden olduğu acı tad giderildiğinde özellikle koyun, keçi ve domuzların beslenmesinde kullanılabilmektedir. Bunula beraber tavşan, kanatlı, sığır ve atların beslenmeleri için yemlerine katılabilir (Akyıldız, 1986). Dünyada koyun ve keçiler, meşe palamudu ve yapraklarıla beslenerek besin madde ihtiyaçlarının büyük bir kısmını temin etmektedir. Bununla birlikte meşe yaprağı ve palamudunun tanen içeriğinin fazla olması sebebiyle sınırlı miktarda kullanılabilmektedir. Meşe yaprağı ve palamudunda bulunan tanenlerin, toksik maddelerle birleşerek bu toksik maddelerin kana geçmesini önlediği bilinmektedir. Bu nedenle meşe palamudu, bakır, kurşun, alkaloidiler ve bunların tuzları ile oluşan toksikasyonlara karşı antidot olarak kullanılabilmektedir (Ikhimioya ve ark., 2008). Adsorban olarak yeme katılan zeolit, ruminant yemlerindeki en önemli etkisi üre metabolizmasında görülmektedir. Üre metabolizmasında, rumende meydana gelen amonyağı adsorbe ederek rumen mikroorganizmalarının mikrobiyal proteini üretmesi için gerekli amonyağın kesintisiz şeklinde rumen ortamında bulunmasını sağlamaktadır (Çolpan ve Yalcın, 1986; Diaz ve ark., 2004; Filya ve ark., 1999). Zeolit rumende oluşan fazla amonyağı adsorbe ederek hayvanda oluşabilecek amonyak toksititesini önlerler. Zeolitin amonyağı adsorbe ederek vücuttan fazla azot atılımının da önüne geçildiği ve dolayısıyla genç ruminantlarda büyümeyi teşvik ettiği de ileri sürülmektedir (Diaz ve ark., 2004; Filya ve ark., 1999; Petkova ve ark., 1983).

$\mathrm{Bu}$ çalışma, ruminant hayvanlar tarafında üretilen ve atmosfere salınan sera gazlarının düşürülmesini araştırmak amacıyla planlanmıştır. Bu amaçla SSR ve YKO'na farklı seviyelerde ilave edilen meşe palamudu, meşe palamudu + zeolit katkısının metan gazı oluşumu, iVOMS, ME değeri, rumen NH3-N parametreleri üzerine etkisini belirlemek amacıyla yapılmıştır.

\section{Materyal ve Metot}

Çalışmada kullanılan süt yemi, saman özel bir işletmede ve yonca kuru otu Harran Üniversitesi Hayvancılık Araştırma Ünitesinden temin edilmiştir. Araştırmada kullanılan meşe palamutları Şanlıurfa Siverek ilçesinin Karpuzcu köyünden toplanmıştır. Araştırmada kullanılan zeolit özel bir şirketten temin edilmiştir. Çalışmada, kullanılan yonca, palamut ve süt sığırı rasyonu $1 \mathrm{~mm}$ elekten geçebilecek biçiminde laboratuvar değirmeninde öğütülerek çalışma için uygun büyüklüğe getirildi. Araştırma yemleri ve meşe palamudunun ham besin madde içerikleri (kuru madde, ham protein ve ham kül) AOAC (1984)'e, ADF ve NDF analizleri ise Van Soest ve ark. (1991)'a göre yapılmıştır. Meşe palamudunun kondanse tanen içeriklerinin belirlenmesi Makkar ve ark. (1995) tarafindan bildirilen yönteme göre yapılmıştır. YKO'u ve SSR na $\% 0$ (kontrol), \%2.5, \%5, \%10 meşe palamudu ve aynı seviyelere \%2.5 zeolit ilave edilerek toplam 16 muamele ve her muamelede 4 tekerrür olacak şekilde düzenlenmiştir. Çalışmada, Menke ve ark. (1988) tarafından bildirilen gaz üretim tekniği kullanıldı. Bu yöntemin temeli yemlerin, rumen sıvısı ile 24 saatlik inkübasyonu sonucu oluşan gaz miktarının ölçülmesine dayanır. Elde edilen sonuçlar, yem maddelerinin IVOMS ve ME içeriğinin hesaplanmasında kullanılmıştır. Elde edilen gaz içerisindeki $\mathrm{CH}_{4}$ bilgisayara bağlı metan gazı ölçüm cihazı (Sensors Analysentechnik GmbH\&Co. KG, Berlin, Germany) yardımıyla belirlenmiştir. 24 saatlik inkubasyondan sonra şırıngalarda kalan rumen sıvısı 4 katlı tülbentten süzülerek $\mathrm{pH}$ 
değerleri okunmuştur. Rumen sıvılarından alınan örnekler $\mathrm{NH}_{3}-\mathrm{N}$ (amonyak azotu) analizlerinin yapılacağı zamana kadar derin dondurucuda $-20{ }^{\circ} \mathrm{C}$ muhafaza edilmiştir. Rumen sıvısının $\mathrm{NH}_{3}-\mathrm{N}$ analizi Markham distilasyon yöntemi ile belirlenmiştir (Markham, 1942).

Elde edilen değerlerin istatistiksel analizi SPSS 13.0 programında tek yönlü varyans (ANOVA) analizi ile yapıldı. Gruplar arasındaki farklııkların önemi Duncan çoklu kıyaslama testiyle belirlendi (SPSS, 2004).

\section{Bulgular}

Yonca Kuru otu ve süt sığırı rasyonuna farklı seviyelerde meşe palamudu ve zeolit ilave edilen grupların besin madde bileşimleri Tablo 1'de verilmiştir. Çalışmada kullanılan yonca kuru otu ve süt sığırı rasyonuna farklı seviyelerde katılmış meşe palamudu ve meşe palamudu + zeolit karışımına ait in vitro gaz üretimi, $\mathrm{CH}_{4}$ ve $\mathrm{CO}_{2}$ gazlarının miktarları, in vitro rumen amonyak azotu, $\mathrm{pH}$ değeri, IVOMS ve ME değerleri sırasıyla Tablo 2 ve 3 'te verilmiştir.

Tablo 1. Farklı seviyelerde meşe palamudu ve zeolit ilavesi yapılan süt rasyonu ve yonca kuru otunun besin madde içeriği.

\begin{tabular}{lcccc}
\hline & \%HP KM & \%HK KM & \%ADF KM & \%NDF KM \\
\hline YKO\%100 & 12.99 & 10.27 & 34.74 & 38.14 \\
YKO97.5+Pa2.5 & 12.76 & 10.07 & 33.97 & 37.70 \\
YKO95+Pa5 & 12.52 & 9.87 & 33.19 & 37.26 \\
YKO90+Pa10 & 12.06 & 9.48 & 31.65 & 36.38 \\
YKO97.5+Z2.5 & 12.67 & 12.51 & 33.87 & 37.19 \\
YKO95+Pa2.5+Z2.5 & 12.43 & 12.31 & 33.10 & 36.75 \\
YKO92.5+Pa5+Z2.5 & 12.20 & 12.12 & 32.33 & 36.30 \\
YKO87.5+Pa10+Z2.5 & 12.13 & 11.72 & 30.78 & 35.42 \\
SSR\%100 & 13.57 & 7.25 & 36.10 & 66.71 \\
SSR97.5+Pa2.5 & 13.32 & 7.13 & 35.29 & 65.55 \\
SSR95+Pa5 & 13.07 & 7.00 & 34.49 & 64.40 \\
SSR90+Pa10 & 12.58 & 6.76 & 32.87 & 62.09 \\
SSR97.5+Z2.5 & 13.23 & 9.57 & 35.20 & 65.04 \\
SSR95+Pa2.5+Z2.5 & 12.98 & 9.45 & 34.39 & 63.89 \\
SSR92.5+Pa5+Z2.5 & 12.73 & 9.32 & 33.58 & 62.73 \\
SSR87.5+Pa10+Z2.5 & 12.24 & 9.08 & 31.97 & 60.42 \\
Pa\%100 & 3.65 & 2.33 & 3.81 & 20.50 \\
\hline SSR:SUt SII
\end{tabular}

SSR:Süt sığııı rasyonu, Pa: Palamut,YKO: Yonca kuru otu, Z: Zeolit, KM: Kuru madde; HK: Ham kül; HP: Ham protein, ADF: Asit deterjanda çözünmeyen lif, NDF: Nötral deterjanda çözünmeyen lif,

Tablo 2. Yonca Kuru otuna farklı seviyelerde ilave edilen meşe palamudu ve zeolitin gaz oluşumuna, metan oluşumuna, karbondioksit, metabolik enerji, amonyak azotu ve in vitro organik madde sindirim derecesi üzerine etkisi.

\begin{tabular}{|c|c|c|c|c|c|c|c|}
\hline & Gaz ml/g KM & $\% \mathrm{CH}_{4}$ & $\% \mathrm{CO}_{2}$ & \%IVOMS, KM & $\begin{array}{c}\mathrm{NH}_{3}-\mathrm{N}, \\
\mathrm{mg} / \mathrm{dl}\end{array}$ & $\begin{array}{c}\text { ME } \\
\mathrm{MJ} / \mathrm{kg} \mathrm{KM}\end{array}$ & pH \\
\hline YKO\%100 & $203,56^{d}$ & $14,71^{\mathrm{a}}$ & $83,47^{b}$ & $57,57^{c}$ & $18,92^{\mathrm{a}}$ & $8,97^{\mathrm{d}}$ & $6,97^{a}$ \\
\hline YK097.5+Pa2.5 & $210,80^{\mathrm{cd}}$ & $14,87^{\mathrm{a}}$ & $83,37^{b}$ & $58,86^{\mathrm{bc}}$ & $18,80^{\mathrm{a}}$ & $9,12^{\mathrm{cd}}$ & $6,92^{\mathrm{ab}}$ \\
\hline YKO95+Pa5 & $213,47^{\mathrm{bcd}}$ & $15,35^{\mathrm{a}}$ & $82,92^{b}$ & $58,87^{b c}$ & $17,41^{\mathrm{a}}$ & $9,07^{d}$ & $6,91^{b}$ \\
\hline YKO90+Рa10 & $223,88^{\mathrm{bc}}$ & $14,84^{\mathrm{a}}$ & $83,51^{b}$ & $61,07^{\mathrm{b}}$ & $16,68^{\mathrm{ab}}$ & $9,49^{b}$ & $6,84^{c}$ \\
\hline YKO97.5+Z2.5 & $203,70 d$ & $14,74^{\mathrm{a}}$ & $83,46^{\mathrm{b}}$ & $57,48^{c}$ & $18,73^{\mathrm{a}}$ & $8,90^{d}$ & $6,93^{\mathrm{ab}}$ \\
\hline YKO95+Pa2.5+Z2.5 & $210,88^{c d}$ & $15,07^{\mathrm{a}}$ & $83,17^{b}$ & $58,64^{\mathrm{bc}}$ & $18,60^{\mathrm{a}}$ & $9,11^{c d}$ & $6,91^{b}$ \\
\hline YKO92.5+Pa5+Z2.5 & $214,94^{\mathrm{bcd}}$ & $14,92^{\mathrm{a}}$ & $83,35^{b}$ & $59,36^{b c}$ & $17,49^{\mathrm{a}}$ & $9,17^{\mathrm{bcd}}$ & $6,90^{b}$ \\
\hline YKO87.5+Pa10+Z2.5 & $226,06^{\mathrm{b}}$ & $14,71^{\mathrm{a}}$ & $83,64^{b}$ & $61,11^{b}$ & $14,79^{b}$ & $9,46^{\mathrm{bc}}$ & $6,89^{b c}$ \\
\hline Pa\%100 & $291,30^{a}$ & $12,67^{b}$ & $86,06^{\mathrm{a}}$ & $68,48^{\mathrm{a}}$ & $7,56^{\mathrm{c}}$ & $10,37^{\mathrm{a}}$ & $6,72^{d}$ \\
\hline SEM & 4,50 & 0,15 & 0,17 & 0,58 & 0,75 & 0,08 & 0,08 \\
\hline $\mathbf{P}$ & $* * *$ & $* * *$ & $* * *$ & $* * *$ & $* * *$ & $* * *$ & $* * *$ \\
\hline
\end{tabular}

Pa: Palamut,YKO: Yonca kuru otu , Z: Zeolit, a,b,c,d,e: Aynı sütünda farklı harf taşıyan değerler farklı bulunmuştur.; ${ }^{* * *}$ : $(\mathrm{P}<0.001) \mathrm{CH}_{4}$ : Metan, $\mathrm{CO}_{2}$ : Karbondioksit, IVOMS: In vitro organik madde sindirimi, $\mathrm{NH}_{3}-\mathrm{N}$ : Amonyak azotu ME: Metabolik enerji. 
Tablo 3. Süt sığırı rasyonuna farklı seviyelerde ilave edilen meşe palamudu ve zeolitn gaz üretimine, metan üretimine, karbondioksit, metabolik enerji, amonyak azotu ve in vitro organik madde sindirim derecesine etkisi.

\begin{tabular}{|c|c|c|c|c|c|c|c|}
\hline & Gaz ml/g KM & $\% \mathrm{CH}_{4}$ & $\% \mathrm{CO}_{2}$ & $\begin{array}{c}\text { \% IVOMS } \\
\text { KM }\end{array}$ & $\begin{array}{r}\mathrm{NH}_{3}-\mathrm{N} \\
\mathrm{mg} / \mathrm{dl} \\
\end{array}$ & $\begin{array}{c}\text { ME MJ/kg } \\
\text { KM }\end{array}$ & $\mathrm{pH}$ \\
\hline SSR100 & $221,34^{b}$ & $15,76^{\mathrm{ab}}$ & $82,57^{\text {cd }}$ & $60,68^{b}$ & $18,840^{\mathrm{a}}$ & $9,55^{b}$ & $6,84^{\mathrm{ab}}$ \\
\hline SSR97.5+Pa2.5 & $222,05^{b}$ & $14,56^{c}$ & $83,76^{b}$ & $60,93^{b}$ & $17,267^{\mathrm{abc}}$ & $9,49^{b}$ & $6,81^{b c}$ \\
\hline SSR95+Pa5 & $223,71^{b}$ & $14,86^{\mathrm{bc}}$ & $83,48 b^{c}$ & $61,10^{b}$ & $16,067^{\mathrm{bc}}$ & $9,52^{b}$ & $6,81^{a b c}$ \\
\hline SSR90+Pa10 & $225,03^{b}$ & $15,64^{\mathrm{ab}}$ & $82,71^{\mathrm{cd}}$ & $60,98^{b}$ & $14,800^{\text {cd }}$ & $9,50^{b}$ & $6,80^{b c}$ \\
\hline SSR97.5+Z2.5 & $221,78^{b}$ & $15,89^{\mathrm{a}}$ & $82,44^{d}$ & $60,64^{b}$ & $17,707^{\mathrm{ab}}$ & $9,48^{b}$ & $6,85^{\mathrm{a}}$ \\
\hline SSR95+Pa2.5+Z2.5 & $222,01^{b}$ & $15,71^{\mathrm{ab}}$ & $82,62^{\mathrm{cd}}$ & $60,68^{b}$ & $16,560^{\mathrm{abc}}$ & $9,44^{b}$ & $6,83^{a b c}$ \\
\hline SSR92.5+Pa5+Z2.5 & $224,80^{b}$ & $15,29^{\mathrm{abc}}$ & $83,07^{\text {bcd }}$ & $61,41^{b}$ & $15,613^{b c d}$ & $9,58^{b}$ & $6,81 b^{c}$ \\
\hline SSR87.5+Pa10+Z2.5 & $232,01^{b}$ & $14,65^{c}$ & $83,78^{b}$ & $62,22^{b}$ & $13,387^{d}$ & $9,64^{a b}$ & $6,80^{c}$ \\
\hline Pa\%100 & $291,30^{\mathrm{a}}$ & $12,67^{d}$ & $86,06^{a}$ & $68,48^{a}$ & $7,560^{\mathrm{e}}$ & $10,37^{\mathrm{a}}$ & $6,72^{a}$ \\
\hline SEM & 3,86 & 0,18 & 0,20 & 0,47 & 0,65 & 0,06 & 0,04 \\
\hline $\mathbf{P}$ & $* * *$ & $* * *$ & $* * *$ & $* * *$ & $* * *$ & $* * *$ & $* * *$ \\
\hline
\end{tabular}

SSR:Süt sığııı rasyonu, Pa: Palamut, Z: Zeolit,a,b,c,d,e: Aynı sütünda farklı harf taşıyan değerler farklı bulunmuştur, $* * *$ : $(\mathrm{P}<0.001) \mathrm{CH}_{4}$ : Metan, $\mathrm{CO}_{2}$ : Karbondioksit, IVOMS: In vitro organik madde sindirimi, $\mathrm{NH}_{3}-\mathrm{N}: A m o n y a k$ azotu, ME: Metabolik enerji.

\section{Tartışma ve Sonuç}

Bu çalışmada meşe palamudu için tespit edilen ham protein, ham kül ADF, NDF ve kondanse tanen içerikleri bazı araştıııııların bulgularıyla uyumlu bulunmuştur (Boubaker ve ark., 2007; Kamalak ve ark., 2004; Rababah ve ark., 2008; Sarıçiçek ve Kılıç., 2002; Yıldız ve ark., 2002). Araştırmada kullanılan YKO'u ve SSR'nun besin madde bileşimleri Tablo $1^{\prime}$ de verilmiştir. Yonca kuru otunun ham besin maddeleri bileşimi yoncanın kalitesine ve vejetasyon dönemine göre değişebilmektedir (Canbolat ve Karaman, 2009; Filya ve ark., 2002). YKO'u ve SSR'na katılmış meşe palamudu seviyesine paralel olarak ADF, NDF ve HP değerlerinin düştüğü tablo 1'de görülmektedir.

Araştırmada SSR'na katılan meşe palamudu + zeolitin metan üretimini azalttığı belirlenmiştir $(P<0.01)$. Rumende metan gazı oluşumunun düşmesi, tanenlerin metanojenik mikroorganizmaların hücrelerinde bulunan protein ve enzimlere bağlanarak oluşturdukları bakterisid ya da bakteriostatik etkilerinden kaynaklanabileceği düşünülmektedir (Tavendale ve ark., 2005). Tanenler ayrıca rumendeki protozoaları etkileyerek metan oluşumunu düşürücü yönde tesir etmektedirler. Tanenler selülozun rumende parçalanmasını sağlayan bakterilerin gelişimlerine etki ederek asetik asittin meydana gelmesini düşürür, bu sebeple rumende metan gazı meydana gelmesi için gereksinim duydukları hidrojen iyonu ile karbondioksitin meydana gelmesini sınırlandırdığı ifade etmektedir (Patra ve Saxena, 2009; Waghorn, 2008). Carulla ve ark. (2005) yaptıkları çalışmalarında rasyona kuru madde yüzdesi \%0.025 seviyesinde akasya bitkisi orijinli tanen eklenmesinin metan gazı oluşumunu \%13 düzeyinde düşürdüğünü belirlemişlerdir. Başka bir çalışmada kaba yeme \%20 seviyesinde akasya bitkisi katılmasının metan gazı oluşumunu önemli derecede düşürdüğü bildirilmiştir (Hariadi ve Santoso, 2010). Jahani-Azizabadi ve ark. (2009) yonca bitkisine, kuru madde esasına göre \%4 seviyesinde biberiye eklenmesinin in vitro metan üretimini istatistiksel olarak önemli derecede düşürdüğünü ifade etmişlerdir. Kestane ağacından eksrakte edilen tanenle yapılan araştırmada, in vitro gaz üretimindeki toplam $\mathrm{CH}_{4}$ gazı oluşumunu azaltııı etki yaptığı bildirilmiştir (Sliwinski ve ark., 2002). Yapılan başka bir çalışmada meşe palamutlarının düşük miktarda kondense tanen içerdiğinden geviş getiren hayvanlar için faydalı olabileceğini belirtmiştir (Kaya, 2012). Yapılan bu çalışmada YKO ve SSR'na meşe palamudu ve meşe palamudu + zeolit ilavesinin rumende $\mathrm{NH}_{3}-\mathrm{N}$ miktarını istatiksel olarak önemli düzeyde azalttığı tespit edilmiştir $(P<0.001)$. Holstein ırkı sığırlara günlük olarak verilen $100 \mathrm{~g}$ ve $200 \mathrm{~g}$ öğütülmüş okaliptüs yaprağının rumen sıvısındaki $\mathrm{NH}_{3}-\mathrm{N}$ miktarı ve metan üreten toplam bakteri sayısını kontrol grubuna göre istatistiksel olarak azalttığı bildirilmiştir (Manh ve ark. 2012). Thao ve Wanapat'ın (2013) yaptıkları in vivo çalışmada, rasyona hayvan başına günlük 40 ve $80 \mathrm{~g}$ ögütülmüş okaliptüs yaprağı ilave edildiğinde rumen sıvısı $\mathrm{NH}_{3}-$ $\mathrm{N}$ düzeyini etkilemediğini $120 \mathrm{~g}$ okaliptüs yaprağı katıldığında ise $\mathrm{NH}_{3}-\mathrm{N}$ düzeyini istatistiksel açıdan azalttığı belirlemişlerdir. Birçok bitkide bulunan tanenlerin uygun miktarda kullanıldığında rumende yıkımlanan protein miktarını azaltarak duedonuma geçen miktarı arttırdığı bildirilmiştir (Carulla ve ark., 2005).

Meşe palamudu ve zeolitin kuru yonca otunun iVOMS'ne etkisi \%57.57 ile \%61.11 arasında değişmiştir. En yüksek iVOMS \%10 meşe palamudu (\%61.07) ve $\% 10$ meşe palamudu $+\% 2.5$ zeolit 
gruplarında (\%61.11) elde edilirken, en düşük iVOMS yonca kuru otu (kontrol) grubunda (\%57.57) saptanmıştır $(\mathrm{P}<0.001)$. Meşe palamudu + zeolitin ilavesine bağlı olarak, iVOMS ve $\mathrm{ME}$ içeriğindeki artış, rumen fermentasyonuna olan olumlu etkisi ile açıklanabilir (Benchaar ve ark., 2007; Calsamiglia ve ark., 2007). Yapılan araştırmalarda zeolitin besi hayvanı rasyonlarına \%1.5-15 seviyelerinde katıldığında hayvan sağlığını bozmadan, hayvanların canlı ağırlığını arttırdığı bildirmişlerdir (Pond, 1989). Yapılan başka bir araştırmada, zeolit rasyona ilave edildiğinde yemden yararlanma oranını iyileştirdiği ve yem tüketimi üzerinde olumsuz etki yapan aflatoksinlerin zararlı etkilerini düşürdüğü, hayvanların karaciğerlerinde biriken mikotoksin miktarlarını azalttığı ve hayvanın genel durumunu iyileştirip, ince bağırsaklarda mannanoligosakkarit üretimini arttırdığı bildirilmektedir (Papaioannou ve ark., 2004; Parlat ve ark., 1999). Çolpan ve ark. (1995) yaptığı çalışmada besiye alınan sığırların konsantre yemine \%1.5 oranında doğal zeolit eklenmesinin besi performansı ile karkas ve kesim özelliklerini olumlu yönde etkilediğini belirlemişlerdir. Besi rasyonuna \%2 seviyesinde doğal zeolit eklenmesi canlı ağırlığı arttırmış, yemi tüketimi ve yemden yararlanmayı iyileştirmiştir (Toker ve Köknaroğlu, 2004). Kuzu rasyonlarına \%24 oranlarında doğal zeolit katılması canlı ağırlığı, kandaki üre ve amonyak azotu seviyelerini yükselttiği, rumen sıvısında üre ve amonyak azotu seviyelerini ise düşürdüğü tespit edilmiştir (Filya ve ark., 1999). Bederski ve ark. (1992) yaptıkları araştırmada meşe yaprağı (Quercus turbinella) tüketmeye alışmış olan keçilerin rumeninde OM sindirilebilirliğinin meşe yaprağı tüketmeye alışmayanlara göre daha yüksek ve hızlı olduğunu bildirmişlerdir. Moujahed ve ark. (2005) yaptığı çalışmada, meşe palamudunun arpayla \%50 oranında ikame edilebileceğini bildirmişlerdir.

Sonuç olarak SSR'na ve YKO'na ilave edilen meşe palamudu ve zeolit, , iVOMS ve ME değerinde artışa ve $\mathrm{CH}_{4}$ gazı oluşumunu azaltabileceği kanısına varılmıştır. Çalışma sonuçları dikkate alındığında meşe palamudu ve meşe palamudu + zeolit katkılarının hayvan performansı üzerine etkilerinin anlaşılmasında in vivo çalışmalara intiyaç vardır.

\section{Kaynaklar}

Akyıldız AR, 1986: Yemler Bilgisi ve Teknolojisi. A. Üniv. Zir. Fak. Yay: 868, Ders Kitabı: 234. A. Üniv. Basımevi, Ankara, S 411.

Animut G, Goetsch AL, Puchala PR, Sahlu T, Varel VH, Wells J, 2008: Methane emission by goats consuming diets with different levels of condensed tannins from lespedeza. Anim Feed Sci Technol, 144,212-227.

AOAC, 1984: Official Methods of Analysis, Association of Official Analytical Chemist, Inc. Arlington, USA.

Bederski HJ, Rice RW, Gomes HS, Ruyle G, Cuneo SP, 1992: Adaptation of goat rumen microflora to tannin rich shrub live oak (Quercus turbinella). American Society of Animal Science, 43, 352-353.

Benchaar C, Petit HV, Berthiaume R, Ouellet DR, Chiquette J, Chouinard PY, 2007: Effects of essential oils on digestion, ruminal fermentation, rumen microbial populations, milk production, and milk composition in dairy cows fed alfalfa silage or corn silage. J Dairy Sci,90, 886-897.

Boubaker AG, Abdouli H, Khelil H, Mouhbi R, Tayaci L, 2007: Nutritional value of cork oak acorn (Quercus Suber L.) as an ernergy source for growing goats.Asian Journal of Animal and Veterinary Advances, 2 (1): 32-37.

Breves G, Leonhard-Marke S, 2000: Verdauungsvorgänge in den Vormägen, in: W. V. Engelhardt and G. Breves. Physiologie der Haustiere. Enke im Hippokrates Verlag GmbH, Stuttgart, 345-354.

Calsamiglia S, Busquet M, Cardozo PW, Castillejos L, Ferret A, 2007: Essential oils as modifiers of rumen microbial fermentation. J Dairy Sci, 90, 2580-2595.

Canbolat Ö, Karaman Ş, 2009: Bazı baklagil kaba yemlerinin in vitro gaz üretimi, organik madde sindirimi, nispi yem değeri ve metabolik enerji içeriklerinin karşılaştırılması. Tar Bil Der, 15 (2): 188195.

Canbolat, Ö, Kalkan, H, Karaman, Ş, Filya, i,2011: Esansiyel yağların sindirim, rumen fermantasyonu ve mikrobiyal protein üretimi üzerine etkileri. Kafkas Üniv Vet Fak Derg, 17 (1): 557-565.

Carulla JE, Kreuzer M, Machmüller A, Hess HD, 2005: Supplementation of Acacia mearnsii tannins decreases methanogenesis and urinary nitrogen in forage-fed sheep. Aust J Agric Res, 56, 961-970.

Çepel N, 2003:Ekolojik Sorunlar ve Çözümleri, Tübitak PopülerBilim Kitapları, Ankara.

Çolpan I, Yalcın S, 1986: Zeolit içeren rasyonların erkek merinos kuzularında yapağı ozelliklerine etkisi. Ankara Üniv Vet Fak Derg, 33(2): 262-272.

Çolpan I, Tuncer ŞD, Önol A, Yıldız G, 1995: Limozin X Jersey (F1) Melezi Tosunlarda Zeolitin Besi Performansı ve Karkas Özelliklerine Etkisi. Lalahan Araş Enst Dergisi, 35 (3-4): 26-43.

Diaz DE, Hagler WM, Blackwelder JT, Eve JA, Hopkins BA, Anderson KL, Jones FT, Whitlow LW, 2004: Aflatoxin binders II: reduction of aflatoxin $\mathrm{M} 1$ in milk by sequestering agents of cows consuming aflatoxin in feed. Mycopathol, 157(2): 233-241.

Doreau M, Martin C, Morgavi DP, Eugene M, 2011: Reducing methane emission in ruminants: is it an achievable goal. In: Ranilla MJ (ed), Carro MD (ed), Ben Salem H (ed), Morand-Fehr P (ed). Challenging strategies to promote the sheep and goat sector in the current global context. Zaragoza, Spain, Universidad de Leon, CIHEAM, CSIC, pp. 65-73. 
Filya I, Karabulut A, Canbolat O, Değirmencioğlu T, Kalkan $\mathrm{H}$, 2002: Bursa bölgesinde yetiştirilen yem hammaddelerinin besleme değeri ve hayvansal organizmada optimum değerlendirme koşullarının in vivo ve in vitro yöntemlerle saptanması üzerinde araştırmalar. Uludağ Üniv Ziraat Fakültesi Bilimsel Araştırmalar ve incelemeler Serisi,25, 1-16, Bursa.

Filya I, Karabulut A, Ak I, Akgunduz V, 1999: Entansif kuzu besisinde zeolit kullanılmasının kuzuların besi performansı ile bazı kan ve rumen sıvisı metabolitleri uzerine etkileri. Hayvansal Üretim,39, 39-48.

Goel G, Makkar HPS, 2012: Methane mitigation from ruminants using tannins and saponins, a status review. Trop Anim Health Prod, 44,729-739.

Guo YQ, Liu JX, Lu Y, Zhu WY, Denman SE, McSweeney CS, 2008: Effect of tea saponin on methanogenesis, microbial community structure and expression of mcrA gene, in cultures of rumen micro-organisms. Lett Appl Microbiol, 47, 421-426.

Hariadi BT, Santoso B, 2010: Evaluation of tropical plants containing tannin on in vitromethanogenesis and fermentation parameters using rumen fluid. J Sci Food Agric, 90, 456-461.

Ikhimioya I, Isah AO, Akhidenor KO, Otite E, 2008: Dry matter degradation parameters of tropical tree foliages eaten by West African dwarf sheep. J App Anim Res, 33,153-158.

Jahani-Azizabadi H, Danesh Mesgaran M, Vakili AR, Heravi Moussavi ARS 2009: Screening the activity of medicinal plants or spices on in vitro ruminal methane production. J Anim Sci,87 E-Suppl. 2/ JDairy Sci,92: E-Suppl. 1, 277-2787.

Kamalak A, Canbolat O, Ozay O, Aktas S, 2004: Nutritive value of oak (Quercus spp.) leaves. Small Ruminant Research, 53, 161-165.

Kaya E, 2012: Farklı meşe türünden elde edilen palamutların potansiyel beslemedeğeri. Yüksek lisans, Kahramanmaraş Sütçü İmam Üniversitesi Fen Bilimleri Enstitüsü, Kahramanmaraş.

Makkar HPS, Blummel M, Becker K, 1995: Formation of complete between Polyvinyl pyrolidones or polyethylene glycol and tannins and their implication in gas production and true digestibility in in vitro technique. BrJ Nutr,73, 897-913.

Manh NS, Wanapat M, Uriyapongson S, Khejornsart $\mathrm{P}$, Chanthakhoun V, 2012: Effect of eucalyptus (Camaldulensis) leaf meal powder on rumen fermentation characteristics in cattle fed on rice straw. African Journal of Agricultural Research,7(14): 2142-2148

Markham R. 1942: Distillation apparatus suitable for microkjeldahl analysis. Biochem J,36, 790.

Menke KH, Steingass H1988: Estimation of the energetic feed value obtained from chemical analysis and in vitrogas production using rumen fluid. Anim Res Dev, 28, 7-55.

Moujahed N, Ben Mustapha C, Kayouli C, 2005: Effect of Barley Replacement by Acorns (Quercus Coccifera L.) as Energy Supplement on In Vitro Fermentation. 11th Seminar of the FAO-CIHEAM Sub-Network on
Sheep and Goat Nutrition. Italy, Catania (I), September 8-10.

Öztürk H, 2008: Ruminant beslemesinde probiyotik mayalar.Veteriner Hekimler Derneği Derg,79(3): 3742.

Papaioannou DS, Kyriakis CS, Alexopoulas C, Tzika ED, Polizopoulou ZS, Kyriakis SC 2004: A Field Study on the Effect of Dietary Use of a Clinoptilolite-rich tuff, Alone or in Combination with Certain Antimicrobials, on the Health Status and Performance of Weaned, Growing and Finishing Pigs. Research in Veterinary Science, 76(1): 19-29.

Parlat SS, Yıldız AO, Oğuz H, 1999: Effect of Clinoplilolite on Performance of Japanese Quail (C. coturnix japonica) During Experimental Aflatoxicosis. Brit Pol Sci, 40, 495-500.

Patra AK, 2010: Meta-analyses of effects of phytochemicals on digestibility and rumen fermentation characteristics associated with methanogenesis. J Sci Food Agric, 90, 2700-2708.

Patra AK, Saxena J, 2009: Dietary phytochemicals as rumen modifiers: A review of the effects on microbial populations. Antonie Van Leeuwenhoek,(96):363-375.

Petkova E, Venkov T, Stanchev KH, 1983: Effect of Bulgarian potassium-calcium zeolites on the assimilation of macro and trace elements in lambs. Vet Med Nauki, 20 (8):36-40

Pond WG, 1989: Effects of Dietary Protein Level and Clinoptilolite on the Weight Gain and Liver Mineral Response of Growing Lambs to Copper Supplementation. Journal of Animal Science, 67, 2772-2781.

Rababah TM, Ereifej KI, Al-Mahasneh MA, 2008: Alhamad MN, Alrababah MA, Muhammad $A H$, The Physicochemical Composition Of Acorns For Two Mediterranean Quercus Species. Jordan Journal of Agricultural Sciences, 4(2): 131-137.

Sağlam NE, Düzgüneş $E$, Balık $i$, 2008: Küresel Isınma ve İklim Değişikliği. Su Ürünleri Dergisi, 25.1.

Sarıçiçek BZ, Kılıç Ü, 2002: Meşe palamutunun yem değerinin belirlenmesi üzerine bir çalışma.Hayvansal Üretim, 43(1): 32-44.

Sliwinski BJ, Soliva CR, Machmüller A, KreuzerM, 2002: Efficacy of plant extracts rich in secondary constituents to modify rumen fermentation. Anim Feed Sci and Tech, 101, 101-114.

SPSS, 2004: Windows User's Guide. Version 13.0, SPSS Inc., Michigan Ave., Illinois, USA., Chicago.

Tavendale MH, Meagher LP, Pacheco D, Walker N, Attwood GT, Sivakumaran S, 2005: Methane production from in vitrorumen incubation with Lotus pedunculatus and Medicago sativa, and effects of extractable condensed tannin fractions on methanogenesis. Anim Feed Sci Technol, 123-124, 403-419

Thao NT, Wanapat M, 2013: Effect of eucalyptus leaf meal supplementation on feed intake ruminal ecology and microbial protein synthesis of swamp buffaloes. Khon Kaen AgrJ, 41(1): 75-79. 
Toker TM, Köknaroğlu H, 2004: Zeolitin ve Besi Bașı Ağırlı̆ı̆ın İsviçre Esmeri Danaların Feedlot Performansı Üzerine Etkileri. 4. Ulusal Zootekni Bilim Kongresi, Eylül, Isparta, 405-40.

Van Soest PJ, Robertson JB, Lewis BA, 1991: Methods for dietary fiber, neutral detergent fiber and nonstarch polysaccharides in relation to animal nutrition. $J$ Dairy Sci,74, 3583-3597.

Waghorn GC, 2008: Beneficial and detrimental effects of dietary condensed tannins for sustainable sheep and goat production-progress and challenges. AnimFeed Sci Technol,147, 116-139.

Woodward SL, Waghorn GC, Lassey KR, Laboyrie PG, 2002: Does feeding sulla (Hedysarum coronarium) reduce methane emissions from dairy cows
Proceedings of the New Zealand. Society of Animal Production, 62, 227-230.

Yıldız S, Oncuer A, Kaya I, Ünal Y, 2002: Effect of tanniferous oak (quercus hartwisiana) leaves on gas production in in vitro rumen fermantation sysytem. Kafkas Univ Vet Fak Derg,8 (2): 139-142.

**Bu araştırma makalesi "Yonca Kuru Otu ve Süt Sığırı Rasyonuna Zeolit ile Meşe Palamudu İlavesinin in Vitro Metan Üretimi Üzerine Etkisi” isimli yüksek lisans tezinden özetlenmiştir.

*Yazışma Adresi: Mehmet AVCI

Harran Üniversitesi, Veteriner Fakültesi, Hayvan Besleme ve Beslenme Hastalıkları Anabilim Dalı, Şanlıurfa, Türkiye e-mail: mavci@harran.edu.tr 